DOI: $10.20396 /$ cel.v62i0.8661313

\title{
(IN)ALIENABILIDADE EM NOMES COMPOSTOS EM APURINÃ (ARUÁK)
}

\author{
(IN)ALIENABILITY IN COMPOUND NOUNS \\ IN APURINÃ (ARAWAK)
}

\author{
MARÍLIA FERNANDA PEREIRA DE FREITAS ${ }^{1}$ \\ SIDNEY DA SILVA FACUNDES ${ }^{2}$
}

\begin{abstract}
Resumo: Discute-se o status dos nomes compostos em Apurinã, quanto à possibilidade de ocorrerem em construções de posse (in)alienável, a partir de dados coletados usando estímulos contextuais até então não utilizados. Os dados coletados por meio do uso desses estímulos contextuais revelaram que se fazem necessárias revisões e ampliações na análise dos padrões de marcação de (in)alienabilidade em nomes compostos em Apurinã anteriormente proposta por Facundes (2000), segundo o qual esses padrões não se aplicariam aos compostos. Freitas (2017) parte das definições de Haspelmath (2008) e Stassen (2009) e define (in)alienabilidade em Apurinã tanto com base na marcação morfológica dos nomes, quanto na sua frequência de ocorrência em textos; nomes inalienáveis têm a posse como parte constitutiva de seus significados, ocorrem mais frequentemente possuídos em textos e são não marcados em construções de posse; dentre os inalienáveis, há i) inalienáveis que podem ter sua posse obrigatória "suspensa" pelo acréscimo do sufixo -txi, a exemplo de $n y$-tikaku ${ }^{3}\left(1 \mathrm{SG}^{4}\right.$-barriga.de $\left.{ }^{5}\right)$ 'minha barriga'/ tikaku-txi (barriga.de-N.POSSD) 'barriga (não se sabe de quem)'; e ii) inalienáveis que não ocorrem com -txi, por exigirem um possuidor 6 , a exemplo de $n$-yry (1SG-pai.de) 'meu pai', mas não *yrytxi (pai, não se sabe de quem)'. Já os nomes alienáveis ocorrem mais frequentemente não possuídos em textos, sendo marcados em construções de posse pelos sufixos $-t e,-n e,-r e_{1}^{7}$ e $-r e$ lexicalmente condicionados, a exemplo de ny-xamynaky-te (1SG-espingarda-POSSD)/ xamynaky 'espingarda'. Os resultados da análise permitiram concluir que, ao mesmo tempo em que os padrões de marcação de
\end{abstract}

${ }^{1}$ Universidade Federal do Pará, UFPA, Belém, PA, Brasil.mfpf@ufpa.br. Orcid: https://orcid.org/0000-0001-7607-6077

${ }^{2}$ Universidade Federal do Pará, UFPA, Belém, PA, Brasil. sidi@ufpa.br Orcid: https://orcid.org/0000-0002-7460-8620

${ }^{3}$ Chave para a ortografia Apurinã: $y=[\mathrm{i}] ; \mathrm{ts}=[\mathrm{ts}] ; \mathrm{th}=[\mathrm{c}] ; \mathrm{tx}=[\mathrm{t} f]$, as demais letras/grafemas seguem o mesmo padrão do português.

${ }^{4}$ Abreviaturas: $1=1^{\text {a }}$ pessoa; $2=2^{\text {a }}$ pessoa; $3=3^{\text {a }}$ pessoa; $\mathrm{SG}=$ singular; $\mathrm{PL}=$ plural; $\mathrm{F}=$ feminino; $\mathrm{M}=$ masculino; $\mathrm{POSSD}=$ possuído $\mathrm{N} . \mathrm{POSSD}=$ não possuído $; \mathrm{NC}=$ nome classificatório, TEMP = temporal; VBLZ = verbalizador; ) = objeto; ALEAT = aleatório; INTR = intransitivizador; $\mathrm{GER}=$ gerúndio; $\mathrm{AUX}=$ auxiliar; INTENS $=$ intensificador; $\mathrm{N} . \mathrm{PROP}=$ nome próprio.

${ }^{5}$ Nomes inalienáveis são glosados desta forma, com "de", por terem a posse como parte constitutiva de suas entradas lexicais, ou seja, são obrigatoriamente possuídos.

${ }^{6}$ Exceto em casos de vocativo, em que a língua conta com algumas poucas formas supletivas, sendo o falante interpretado como o possuidor, nesses casos.

${ }^{7}$ Os números subscritos em -re, e -re indicam que, embora sincronicamente tais sufixos apresentem a mesma forma, diacronicamente tềm origens diferentes, conforme reconstrução feita por Payne (1991). Adicionalmente, nomes marcados por -re ${ }_{2}$ formam um subconjunto de alienáveis que recebem marcação não só na forma possuída, mas também na forma não possuída pelo sufixo -ry. 
(in)alienabilidade aplicam-se aos nomes compostos produtivos, eles também indicam que os nomes compostos produtivos marcados como (in)alienáveis são usados em contextos mais específicos e menos frequentes no cotidiano, ou em neologismos, e que, portanto, eles não se comportam pragmaticamente como os nomes (in)alienáveis mais prototípicos em Apurinã.

Palavras-chave: (In)alienabilidade; nomes compostos; Apurinã.

\begin{abstract}
The status of compound nouns in Apurinã is discussed regarding the possibility of occurring in constructions of (in)alienable possession, based on data collected using contextual stimuli not previously used in Apurinã data collection. The use of contextual stimuli in data collection led to a revision and expansion of the analysis of the (in)alienability marking patterns in compound nouns in Apurinã. Facundes (2000) argued that the morphological marking patterns of (in)alienable nouns do not apply to compounds. Freitas (2017) starts from the definitions of Haspelmath (2008) and Stassen (2009) and analyzes (in)alienability in Apurinã based both on the morphological marking of nouns, and on their frequency of occurrence in texts; inalienable nouns have possession as part of their meanings, occur most often possessed in texts and are unmarked in possession constructions; among the inalienable nouns, there are i) inalienable nouns that can have their mandatory possession "suspended" by adding the suffix -txi, as in ny-tikaku (1SG-belly.of) 'my belly' / tikaku-txi (belly.ofN.POSSD) 'belly', and ii) inalienable nouns that do not occur with -txi, as they require a possessor, as in n-yry (1sg-pai.de) 'my father', instead of *yry-txi (someone's father). Alienable nouns, on the other hand, occur most frequently not possessed in texts, being marked in possession constructions by the suffixes -te, -ne, -re ${ }_{1}$ and -re ${ }_{2}$, lexically conditioned, such as ny-xamynaky-te (1SG-shotgun-POSSD) / xamynaky 'shotgun'. The results of the analysis allowed us to conclude that, while the (in)alienability marking patterns also apply to productive compound nouns, they also indicate that the productive compound nouns marked as (in)alienable are used in more specific contexts, and less frequently in everyday life, or are neologisms, and that, therefore, they do not behave pragmatically like prototypical (in)alienable nouns in Apurinã.
\end{abstract}

Keywords: (In)alienability; compound nouns; Apurinã.

\title{
1. CONSIDERAÇÕES INICIAIS
}

Apurinã é uma língua indígena da família Aruák, falada pelo povo de mesmo nome (Pupỹkarywakury na língua), ao longo de vários afluentes do Rio Purus, principalmente no estado do Amazonas e, no caso de algumas poucas famílias, em terra indígena de etnia de origem Tupi, no estado de Rondônia, e na periferia da cidade de Rio Branco, no Acre. Apesar de essa língua já contar com vários trabalhos linguísticos descritivos, sendo o principal deles a gramática elaborada por Facundes (2000), havia, e ainda há, várias questões mais específicas que ainda carecem de uma descrição mais acurada e que vêm sendo tratadas em outros estudos nos últimos anos. Entre essas questões está o status dos nomes compostos, em relação aos outros nomes na língua, especialmente em se tratando da possibilidade de sua ocorrência (ou não) em construções de posse.

Segundo Facundes $(1994,2000)$, salvo algumas exceções, nomes compostos não subcategorizam para (in)alienabilidade, ou seja, tais nomes não recebem os padrões de marcação de posse alienável e inalienável em Apurinã. Entretanto, Freitas (2017) apresentou novos exemplos de compostos na língua que podem ocorrer em construções de posse alienável e inalienável, a depender de questões contextuais, o que exige, como será demonstrado neste trabalho, uma reinterpretação da análise originalmente proposta por Facundes em relação aos padrões de marcação de posse na língua. 
Neste artigo, inicialmente, será apresentada uma caracterização morfossintática dos nomes em Apurinã, mostrando a classificação mais atual destes, proposta em Freitas (2017). Em seguida, será feito um detalhamento, com base em Facundes (2000), das principais características de nomes compostos e suas subclasses. Por fim, com base nos novos dados textuais e lexicais encontrados em Freitas (2017), será demonstrado como os nomes compostos produtivos em Apurinã funcionam em construções de posse alienável e inalienável. Dado que os compostos produtivos são, em geral, constituídos de (pelo menos) uma palavra livre combinada com um ou mais morfemas lexicais com função classificatória, e seguindo o padrão morfológico da língua, tais compostos estão, gramaticalmente, na interface entre morfologia e sintaxe. Além disso, os usos dos compostos produtivos somente podem ser compreendidos levando em consideração as relações semânticas de metáfora, metonímia e meronímia, portanto, na interface entre a morfossintaxe e a semântica lexical.

\section{OS NOMES EM APURINÃ}

Na língua Apurinã, os nomes são definidos morfossintaticamente com base em quatro parâmetros, quais sejam: gênero (masculino e feminino), número (singular e plural), ocorrência com as formas pronominais (livres e presas) e, em consequência deste último, posse (não possuível, inalienável e alienável).

Quanto ao primeiro parâmetro, a língua apresenta os gêneros masculino, marcado pelo sufixo -ry, como em hãtaku-ry (jovem-M) 'rapaz'; e feminino, codificado pelo sufixo -ru, como em hãtaku-ru (jovem-F) 'moça'. Ocorre que o gênero na língua nem sempre vem expresso morfologicamente em bases nominais, uma vez que, em muitos casos, o gênero precisa ser armazenado juntamente com a entrada lexical de cada nome, como em ãata 'canoa tradicional', um nome feminino (cf. uwa ãata 'essa canoa'), ou kupiti 'pote de barro', palavra masculina (cf. ywa kupiti 'esse pote de barro').

Em se tratando da marcação de número gramatical, a língua conta com o sufixo -waku (que se atrela a referentes humanos), seguido das marcas de gênero -ry e -ru, como em sytu-waku-ru (mulher-PL-F) 'mulheres' e kyky-waku-ry (homemPL-M) 'homens'. Ainda, há o sufixo -ny (que ocorre com referentes humanos e não humanos), seguido das marcas de gênero, como em sytu-ny-ru (mulher-PL-F) 'mulheres' e aiku-ny-ry (casa-PL-M) 'casas'.

Apurinã conta com uma série de formas pronominais livres (nuta 'eu', pithe 'você', ywa 'ele', uwa 'ela', atha 'nós', hỹthe 'vocês', ynawa/nynawa/ynuwa/ nynuwa ${ }^{8}$ 'eles ou elas') e também com proclíticos pronominais ${ }^{9}$ (ny- 'eu', py'você', $y$ - 'ele', $u$ - 'ela', $a$ - 'nós', $h \tilde{y}$ - 'vocês', $y$-....-na 'eles', $u$-....-na 'elas') que

${ }^{8}$ Há variação dialetal na terceira pessoa do plural em Apurinã, em que as quatro formas são possíveis na língua.

${ }^{9}$ Que apresentam alomorfes fonologicamente condicionados (cf.: FACUNDES, 2000). 
antecedem nomes possuídos, codificando o possuidor ${ }^{10}$. Assim, tais pronomes, ao serem antepostos a nomes, expressam a pessoa e número do possuidor em construções de posse inalienável ou alienável, seguindo os padrões de marcação morfológica de cada nome, conforme explanado a seguir.

A categoria de posse, por ser um traço universal das línguas do mundo, conta com uma ampla literatura linguística (cf.: NICHOLS, 1988; HEINE, 2001; BARON e HERSLUND, 2001; HASPELMATH, 2008; STASSEN, 2009; entre outros). De modo geral, se refere, semanticamente, a uma relação que pressupõe a existência de dois participantes: um possuidor e um item possuído (STASSEN, 2009). Várias foram as propostas de classificação de nomes em Apurinã, quanto a seus padrões de marcação de posse alienável e inalienável (cf.: FACUNDES, 1994, 1995 e 2000; BRANDÃO, 2006; FACUNDES e FREITAS, 2013). A mais atual e que contou com uma pesquisa mais sistemática, entretanto, corresponde à proposta por Freitas (2017), que subdivide os nomes na língua em três grandes grupos: i) nomes não possuíveis; ii) nomes inalienáveis; iii) nomes alienáveis. Os primeiros são aqueles a que a categoria de posse não se aplica, referindo-se a nomes próprios e certos nomes genéricos com traço [+humano], como kãkiti 'gente'.

Freitas (2017) caracteriza a (in)alienabilidade em Apurinã levando em conta não só os padrões de marcação morfológica dos nomes, mas também sua ocorrência em textos. Assim, um nome inalienável é aquele cuja posse é parte integrante de sua entrada lexical (obrigatoriamente possuído), que ocorre mais frequentemente possuído do que não possuído em textos e que é não marcado por sufixos de posse quando possuído. Há uma subdivisão interna dos inalienáveis, em que constam dois subgrupos: i) nomes inalienáveis (exemplo 1) que podem ter sua posse obrigatória "suspensa", quando do acréscimo do sufixo - $t x i$, semanticamente englobando as partes do corpo, conceitos relacionados ao corpo (metaforicamente ou não), pertences individuais e alguns conceitos abstratos; e ii) nomes inalienáveis que não ocorrem com -txi, pela impossibilidade de serem utilizados na ausência de um possuidor, incluindo exclusivamente os termos de parentesco (exemplo 2).

(1) a. y-kakuta

3SG-bochecha.de

'bochecha dele'

(2) a. $n^{11}$-atukyry

1SG-avô.de

'meu avô' b. kakuta-txi

bochecha.de-N.POSSD

'bochecha (não se sabe de quem)'

b. *atukyry-txi

avô.de-N.POSSD

(avô, não se sabe de quem)

Os nomes alienáveis, por seu turno, têm a posse como uma categoria opcional, ocorrem mais frequentemente não possuídos do que possuídos em textos

${ }^{10}$ Construções de posse nominal também se dão por justaposição de um nome possuidor e um nome possuído, nesta ordem.

${ }^{11}$ Em Apurinã, a forma pronominal proclítica de primeira pessoa do singular $n y$ - sofre alomorfia fonologicamente condicionada. Assim, /ny-/ passa a /n-/, quando diante de vogal. 
e são marcados por um conjunto de sufixos na forma possuída, cuja escolha é lexicalmente condicionada, muito embora seja possível prever alguns padrões, com base em questões de ordem semântica, pragmática e morfossintática (cf.: FREITAS, 2017). Há também uma subdivisão entre os nomes alienáveis, em que constam dois subconjuntos: i) nomes alienáveis marcados na forma possuída por -re ${ }_{1}$, te e -ne (3-5); e ii) nomes alienáveis marcados por -re ${ }_{2}$ na forma possuída e por -ry na forma não possuída (6):
(3) a. y-pĩtxita ${ }^{12}$-re
3SG.M-pente-POSSD
'pente dele'
b. pĩtxita
pente
'pente'
(4) a. ny-katarukyry-te
1SG-farinha-POSSD
'minha farinha'
b. katarukyry
farinha
'farinha'
(5) a. n-atukatxi-awĩthe-ne
1SG-sol-chefe.de-POSSD
'meu relógio'
b. atukatxi-awithe
sol-chefe.de
'relógio'
(6) a. nhi $^{13}$-txipuku-re
1SG-fruta-POSSD
'minha fruta'
b. txipuku-ry
fruta-N.POSSD
'fruta'

Acima, foram mostrados exemplos da ocorrência dos proclíticos codificando a pessoa e número do possuidor, quando antepostos a nomes, o que também pode ocorrer com os pronomes livres, como em atha aiku-ny-ry-te (1PL casa-PL-MPOSSD) 'nossas casas', um caso de posse alienável, em que se requer a presença de um sufixo de posse, nesse caso, -te; e pithe nyrymany-waku-ry (2SG irmão. de-PL-M) 'teus irmãos', exemplo de construção de posse inalienável, sendo que este último tipo de construção não requer qualquer sufixo de posse, uma vez que inalienáveis são não marcados em construções de posse, diferindo dos alienáveis, que recebem sufixos de posse, como visto anteriormente. Note-se que, em Apurinã, assim como em outras línguas da família Aruák, o proclítico pessoal indexa apenas pessoa, número e, no caso da terceira pessoa, gênero, mas não codifica a posse em si. Compare-se, por exemplo, o uso de $y$ - em (1a) e (3a): no primeiro caso, a noção de posse está presente, mas não é marcada morfologicamente no nome y-kakuta 'bochecha dele' - a não ser pela ausência dos sufixos marcadores de posse, enquanto que no segundo caso a noção de posse está presente e é marcada pelo sufixo -re no nome y-pĩtxita-re 'pente dele'.

Há de se mencionar, ainda, os casos de posse indireta, estratégia preferencial dos Apurinã, quando da expressão de posse de um animal ou de elementos da

\footnotetext{
${ }^{12}$ Empréstimo da forma "pente", em português, adaptado para a fonologia Apurinã.

${ }^{13}$ Este é um entre três alomorfes do proclítico de primeira pessoa do singular em Apurinã, uma vez que, nesse caso, /ny-/ passa a /nhi-/, diante de um segmento palatal.
} 
natureza, como em ny-pyra pathary (1SG-criação-de galinha) 'minha galinha', literalmente significando 'minha criação (de) galinha'.

Quanto ao uso de sintagmas nominais codificando o possuidor, estes precedem o item possuído, como em Pymãi tikaku (N.PROP barriga.de) 'barriga da Pymãi' e Pymãi atukyry tikaku (N.PROP avô.de barriga.de) 'barriga do avô da Pymãi', exemplos de posse inalienável; em Iuykake kanawa-te (N.PROP canoaPOSSD) 'canoa do Iuykake', tem-se um exemplo da ocorrência de sintagma nominal expressando o possuidor com um nome alienavelmente possuído.

Após esta breve descrição relativa às construções de posse e, mais acima, referente à morfossintaxe de nomes em Apurinã, cabe dizer ainda que, na língua, do ponto de vista de sua constituição interna, há nomes simples, formados por uma única raiz nominal (podendo ser classificatórios ou não classificatórios) e nomes compostos, que contêm mais de uma raiz nominal (podendo ser produtivos ou não produtivos). Compostos são produtivos em Apurinã quando carregam na sua estrutura um nome classificatório. Nomes classificatórios foram inicialmente descritos em Facundes (1994) e podem ser definidos como formas presas, inalienáveis, recorrentes, com funções classificatórias que participam da formação de nomes compostos. Tais compostos são usados produtivamente quando o nome classificatório que o compõe é usado com extensões metafóricas ou metonímicas. Semanticamente, os nomes classificatórios designam propriedades de forma, textura e consistência.

Facundes (2000) considera que os padrões de marcação de posse inalienável e alienável se aplicam apenas a nomes simples. No entanto, observando-se dados como os do exemplo em (5a) n-atukatxi-awĩthe-ne 'meu relógio', constituído por duas raízes nominais, verifica-se que tal nome composto admite marcação de posse alienável. Por conta de casos como este é que se buscou compreender de modo mais sistemático que fatores estariam implicados no uso de compostos em construções de posse (em que se atestou a interferência de fatores contextuais), diferentemente daquilo proposto em Facundes (2000), o que será discutido a partir da próxima seção.

\section{NOMES COMPOSTOS EM APURINÃ}

Conforme Facundes (1994, 2000), nomes compostos em Apurinã podem ser produtivos ou não produtivos. Nomes compostos produtivos são constituídos de uma raiz mais, pelo menos, um nome classificatório. Nomes classificatórios são nomes presos inalienáveis que ocorrem frequentemente em compostos, com funções classificatórias, salientando semanticamente propriedades de forma, textura e consistência, a exemplo de xamy-na-ky (fogo-NC.linear.de ${ }^{14}-\mathrm{NC}$. pequeno.de) 'espingarda', teny-pẽ (seio.de-NC.líquido.de) 'leite materno'). Nomes compostos não produtivos são formados por mais de uma raiz, não apresentando

${ }^{14}$ Uma vez que pertencem à classe dos nomes inalienáveis, também os nomes classificatórios são glosados com “de”, já que a posse também faz parte da entrada lexical de tais nomes. 
qualquer padrão produtivo, em se tratando de seus elementos constitutivos ou de seus significados derivados, a exemplo de pirũty-awithe (beija.flor-chefe. de) 'avião' e atukatxi-awĩthe (sol-chefe.de) 'relógio'. Deve-se notar, contudo, em relação à forma awĩthe, que aparece nesses dois exemplos, que se trata de um nome inalienável que designa 'líder' de animais em um grupo/bando, cuja forma não possuída é awĩthetxi, que mais recentemente tem sido também usada para designar 'cacique'. O uso dessa forma em pirüty-awithe e atukatxi-awithe é, portanto, metafórico, o que sugere que awĩthe comporta-se também como um nome classificatório. Neste caso, pirüty-awĩthe e atukatxi-awĩthe são também nomes compostos produtivos. Assim, nomes compostos não produtivos são menos comuns em Apurinã do que Facundes outrora indicou.

Facundes (2000) postula que tais compostos evoluíram a partir de nomes simples lexicalmente marcados como inalienáveis, já que estes últimos sempre podem ocorrer em construções de posse por justaposição. Segundo o autor:

Como elementos lexicais, nomes simples inalienáveis frequentemente podem ocorrer como o elemento possuído (uma vez que [...] são lexicalmente marcados como obrigatoriamente possuídos), tornando-se fonologicamente atrelados ao nome possuidor" (FACUNDES, 2000, p.213, tradução nossa).

O status produtivo dos compostos que contêm nomes classificatórios na sua estrutura é, portanto, efeito da frequência de ocorrência de nomes inalienáveis em construções nominais de posse. Como foi demonstrado em Freitas (2017), uma das principais distinções entre nomes inalienáveis e nomes alienáveis em Apurinã é que os primeiros ocorrem com maior frequência como o elemento possuído em construções possessivas. $\mathrm{O}$ fato de a posse inalienável envolvendo formas lexicais ser marcada por justaposição e o fato de haver uma alta frequência de ocorrência de nomes inalienáveis como elementos possuídos favorecem a perda de proeminência prosódica e a consequente mudança de um sintagma nominal para um nome composto. Dessa forma, o sintagma nominal [hã'giti 'mata] (onça couro/pele) 'couro da onça' perde a autonomia prosódica do primeiro nome e torna-se [hã.giti 'mata] 'couro da onça'. Além disso, mata passa a ser usado com um sentido metafórico, como em kiti-matã ${ }^{15}$-txi (pé-couro/pele-N.POSSD) 'sandália' e adquire uma função classificatória, expressando características planas, chatas da superfície de certos objetos.

Neste ponto, há que se destacar uma importante generalização proposta por Facundes (2000), segundo a qual “[...] nomes compostos, em geral, não subcategorizam para (in)alienabilidade" (p.210). De acordo com o autor, apenas nomes simples poderiam receber os padrões de marcação morfológica de nomes inalienáveis e alienáveis. A palavra nuky-tsa-txi (pescoço.de-NC.cipó. de-N.POSSD) 'colar' é tratada como exceção, sendo o único caso atestado pelo autor de um composto produtivo ocorrendo com o sufixo -txi, que, como visto

${ }^{15}$ Ocorre uma nasalização da vogal final de certos nomes a que -txi se liga, o que parece ser determinado por um condicionamento lexical. 
anteriormente, marca o subconjunto de nomes inalienáveis na forma não possuída, excluindo-se os termos de parentesco.

Freitas (2017), no entanto, apresenta vários dados de textos, além daqueles coletados com a aplicação de questionários lexicais em que ocorrem diversos casos de compostos produtivos e não produtivos com marcações de posse alienável e inalienável, como em (7):

$\begin{array}{cllll}\text { (7) Pupỹkary } & \text { ithupa } & \text { syka-saaky } & \text { atama-ta-ry } & \text { erẽka-txi } \\ \text { apurinã } & \text { mata } & \text { dar-TEMP } & \text { ver-VBLZ-3SG.M.O } & \text { sangue.de-N.POSSD }\end{array}$

'O índio estava andando na mata e viu um rastro de sangue.' Lit.: 'Quando deu (chegou) na mata, o índio viu sangue.'

$\mathbf{Y}^{16}$-ẽrẽka-tikinhi $\quad \boldsymbol{\emptyset}^{17}$-iãkyny-tikinhi $\quad$ sã-ãpu-ta apuka-ry $\quad$ ø-apy.

3sG.M-sangue.de-atrás 3sG.M-rastro.de-atrás ir-ALEAT-VBLZ achar-3sG.M.o 3sG.M-osso

'Ele seguiu o rastro e encontrou um osso.' Lit.: 'Atrás do sangue dele, atrás do rastro dele, foi e achou osso'

Em (7), as formas yẽrẽkatikinhi 'atrás do sangue dele' e iãkynytikinhi 'atrás do rastro dele' são formadas por raízes inalienáveis mais o que Facundes (2000) chama de marca de oblíquo. Embora tikinhi se comporte como uma posposição nessas duas palavras, yẽrẽkatikinhi e iãkynytikinhi são nomes em Apurinã, pois ocorrem na forma possuída e preservam traços nominais (assim com back 'costas' ou top 'topo' em inglês), o que justifica tratar yẽrêkatikinhi e iãkynytikinhi como compostos não produtivos inalienavelmente possuídos. A seguir, um outro exemplo da ocorrência de compostos com marcação de posse inalienável:

(8) Ikanapiriã-saaky ywa amuta-ry y-sãkira-wa-t-inhi, voltar-TEMP $\quad 3$ SG.M comprar-3sG.M.o 3sG.M-falar-INTR-VBLZ-GER

ø-iũka-tsupa-t-inhi.

3SG.M-pinta,marca.de-folha.de-VBLZ-GER

'Quando ele voltou, ele comprou o celular dele e o computador dele.'

No exemplo (8), o falante Apurinã criou os neologismos ysãkirawatinhi 'celular' e iükatsupatinhi 'computador'. O primeiro é derivado do verbo sãkirawata 'falar' na forma do gerúndio, portanto, um nome composto diferente dos produtivos e não produtivos propostos por Facundes (2000). O segundo deriva do verbo iũkatsupata 'escrever' na forma do gerúndio. Do ponto de vista semântico, uma vez que 'celular' e 'computador' são objetos que chegaram

\footnotetext{
${ }^{16}$ Em algumas variedades da língua Apurinã, como resultado de variação dialetal, o proclítico de $3^{\text {a }}$ pessoa do singular masculino não passa a /ø-/, quando diante de vogais nasais. Nas variedades em que isto ocorre, este proclítico passa a /ø-/ apenas diante de vogais não nasais.

${ }^{17} \mathrm{O}$ proclítico de $3^{\mathrm{a}}$ pessoa do singular masculino sofre alomorfia fonologicamente condicionada nesse caso, em que /y-/ passa a /ø-/ diante de vogal.
} 
relativamente recentemente na cultura Apurinã, o falante escolheu a estratégia de criar, com o que havia disponível na língua, nomes para designar tais referentes, obviamente, com base em sua percepção acerca dos usos que ele faz do celular. $\mathrm{O}$ celular serve para "falar", daí a escolha da forma sãkirawata; o computador serve para "escrever", por isso foram escolhidos os conceitos "pinta/ marca" e "folha", nomes que formam o verbo iũkatsupata 'escrever', conceito que também não é "nativo" da cultura Apurinã, língua indígena de tradição oral.

Ainda com base nos dados de Freitas (2017), observam-se mais casos de compostos, a maioria deles envolvendo nomes classificatórios. Entre tais dados, constam dezenas de exemplos da ocorrência de compostos com o sufixo -txi (como em nukytsatxi 'colar', único exemplo atestado por FACUNDES, 2000). Abaixo, o Quadro 1, apresentado pela autora, mostra esse tipo de ocorrência:

Quadro 1: Compostos com marcação de não posse -txi.

\begin{tabular}{|c|c|}
\hline Forma não possuída & Glosa \\
\hline$u k y$-pitẽ-txi (olho.de-pelo, pena.de-n.possd) & 'sobrancelha' \\
\hline uky-mata-txi (pálpebra.de-nc.pele.de-n.possd) & 'pálpebra' \\
\hline$u k y$-tãta-txi (olho.de-nc.casca.de-n.possd) & ‘óculos’ \\
\hline tẽẽ-ta-txi (testa.de-nc.borda.boleada.de-n.possd) & 'testa' \\
\hline kaku-ta-txi (bochecha.de-nc.borda.boleada.de-n.possd) & 'bochecha' \\
\hline tsyrỹy-ta-txi (dente.de-nc.borda.boleada.de-n.possd) & 'dentadura' \\
\hline kiri-tã-txi (nariz.de-nc.borda.boleada.de-n.possd) & 'nariz' \\
\hline $\begin{array}{l}\text { kiri-ta-xike-txi (nariz.de-nc.borda.boleada.de-nc.cabelo.de-n. } \\
\text { possd) }\end{array}$ & 'cabelo do nariz’ \\
\hline$x i-\tilde{a}-p u t u-t x i$ (nc.cabelo.de-loc-lábio.de-n.possd) & 'barba ou bigode' \\
\hline kanu-ke-txi (braço.de-nc.vara.de-n.possd) & 'braço’ \\
\hline kanu-ke-xike-txi (perna.de-nc.vara.de-nc.cabelo.de-n.possd) & 'pelo do braço' \\
\hline tapi-ke-txi (perna.de-nc.vara.de-n.possd) & 'perna' \\
\hline tapi-ke-xike-txi (perna.de-nc.vara.de-nc.cabelo.de-n.possd) & 'pelo da perna' \\
\hline puri-ke-txi (coxa.de-nc.vara.de-n.possd) & 'coxa’ \\
\hline xurũky-pytsa-txi (cordão.umbilical.de-nc.cipó.longo.flexível.de) & 'cordão umbilical' \\
\hline$n u k y$-tsa-txi (pescoço.de-nc.cipó.de-n.possd) & 'colar' \\
\hline waku-nuta-txi (mão.de-?-n.possd) & 'pulso' \\
\hline piu-ki-txi (mão.de-nc.pequeno.de-n.possd) & ‘dedo da mão’ \\
\hline kiti-ki-txi (pé.de-nc.pequeno.de-n.possd) & 'dedo do pé’ \\
\hline kiti-matã-txi (pé.de-nc.casca.de-n.possd) & ‘sandália' \\
\hline tsyna-ã-txi (urina.de-nc.líquido.de-n.possd) & 'urina' \\
\hline iẽnama-ã-txi (saliva.de-nc.líquido.de-n.possd) & 'saliva' \\
\hline ãtsã-ã-txi (lágrima.de-nc.líquido.de-n.possd) & 'lágrima’ \\
\hline
\end{tabular}


ii-pe-txi (gordura.de-nc.pastoso.de-n.possd)

'gordura'

xiri-pi-txi (flecha.de-nc.fino, flexível.de-n.possd)

'flecha'

Fonte: Freitas (2017, p.218).

Facundes (2000) afirma haver alguns casos excepcionais de ocorrência de compostos, quase sempre envolvendo nomes classificatórios, com os sufixos de posse alienável -te ou -ne, conforme o Quadro 2, apresentado pelo autor:

Quadro 2: compostos produtivos com marcação de posse alienável.

\begin{tabular}{|c|c|c|}
\hline Forma não possuída & Forma possuída & Glosa \\
\hline$i \tilde{a} r \tilde{\imath}-i \tilde{a}$ & -iãrĩ-iã-te & 'bebida' \\
\hline$\tilde{a} a-m y n a$ & -ãa-myna-te & ‘árvore’ \\
\hline$\tilde{a} a-t s u p a$ & -ãa-tsupa-te & 'folha' \\
\hline 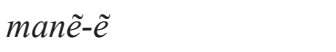 & 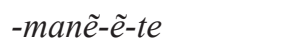 & 'boca do rio' \\
\hline kai-suru & -kai-suru-te & 'pedra de amolar' \\
\hline xamy-puky & -xamy-puky-te & 'fogão de lenha' \\
\hline xamy-na-ke & -xamy-na-ke-te & 'espingarda' \\
\hline ãata-panhi & -ãata-panhi-ne & 'cinza' \\
\hline sawata-pa & -sawata-pa-ne & ‘sapato’ \\
\hline etc. & & \\
\hline
\end{tabular}

Fonte: Facundes (2000, p.212, tradução nossa).

Freitas (2017), por seu turno, como mostra o Quadro 3, acrescenta aos dados de Facundes (2000) uma lista com mais casos da ocorrência de compostos com sufixos de posse alienável, em que figuram não apenas os sufixos -te e -ne, mas também os outros dois sufixos de posse alienável, -re (apenas três casos) e -re ${ }_{2}$ (apenas um caso). Novamente, a maioria desses compostos contém nomes classificatórios e, portanto, são compostos produtivos.

Quadro 3: Compostos com marcação de posse alienável -te, -ne, -re $e_{1} \mathrm{e}-r e_{2}$.

\begin{tabular}{|c|c|}
\hline Forma possuída & Glosa \\
\hline nhi-xãmy-na-te (1sg-fogo-nc.linear.de-possd) & 'meu fogo' \\
\hline $\begin{array}{l}n \text {-ãa-pytsa-te (1sg-nc.planta.de-nc.fino, comprido- } \\
\text {-possd) }\end{array}$ & 'meu cipó, corda' \\
\hline$n y-k \tilde{y} y r y-k y$-te (1sg-rato-nc.pequeno-possd) & 'meu rato' \\
\hline n-akiri-ky-te (1sg-mutucão-nc.pequeno-possd) & 'meu mutucão (inseto)' \\
\hline n-ãkiti-xima-te (1sg-onça-peixe-possd) & 'caparari' \\
\hline ny-äputa-sãny-te (1sg-abano-caba-possd) & 'marimbondo de chapéu' \\
\hline $\begin{array}{l}\text { ny-kaikiri-pi-ne (1sg-jacaré-nc.comprido, flexível. } \\
\text { de-possd) }\end{array}$ & 'meu jacaré' \\
\hline
\end{tabular}




\begin{tabular}{|c|c|}
\hline ny-suty-ãwithe-ne $e^{18}$ (1sg-veado-chefe.de-possd) & 'meu carneiro' \\
\hline n-ixiwa-ãwĩthe-te ${ }^{19}$ (1sg-tamanduá-chefe.de-possd) & 'meu cavalo' \\
\hline ny-kema-ãwithe-ne $e^{20}$ (1sg-anta-chefe.de-possd) & 'meu boi, vaca' \\
\hline ny-miriti-awithe-te (1sg-caititu-chefe.de-possd) & 'meu porco (doméstico)' \\
\hline $\begin{array}{l}n \text {-atã-kaari-te }{ }^{21} \text { [ãta-kawãary] (1sg-beber-igarapé- } \\
\text {-possd) }\end{array}$ & 'meu espelho' \\
\hline $\begin{array}{l}\text { ny-lätenha-myna-te (1sg-lanterna-nc.cilíndrico. } \\
\text { de-possd) }\end{array}$ & 'minha lanterna' \\
\hline n-atukatxi-awithe-ne (1sg-sol-chefe.de) & 'meu relógio' \\
\hline $\begin{array}{l}n y \text {-kai-suru-ky-te (1sg-pedra-substância.rugosa-nc. } \\
\text { pequeno-possd) }\end{array}$ & 'meu colar de pedra' \\
\hline $\begin{array}{l}\text { nhi-xamy-na-ky-panhi-te (1sg-fogo-nc.linear.de-nc. } \\
\text { pequeno.de-possd) }\end{array}$ & 'minha pólvora' \\
\hline $\begin{array}{l}n y-x \tilde{u} p u-k y-t e^{22} \text { (1sg-chumbo-nc.redondo, pequeno. } \\
\text { de-possd) }\end{array}$ & 'meu chumbo' \\
\hline$k a-t s y y-p \tilde{e}-r u$-te (atrib-dor.de-nc.líquido.de-f-possd) & 'minha cachaça' \\
\hline$n$-anana-pẽ-te $e^{23}$ (1sg-abacaxi-nc.líquido.de-possd) & 'meu vinho de abacaxi' \\
\hline $\begin{array}{l}\text { n-asîka-pi-re }{ }_{1}(1 \mathrm{sg} \text {-chupar, sugar-nc.comprido, } \\
\text { flexível.de-possd) }\end{array}$ & 'meu cigarro' \\
\hline ny-pittxi-ta-re $(1$ sg-pente-nc.borda.boleada-possd) & 'meu pente' \\
\hline ny-ãa-txapata-re ${ }_{1}$ (1sg-nc.planta.de-forquilha-possd) & 'minha forquilha' \\
\hline$n y$-kana-ã-re ${ }_{2}$ (1sg-vômito-nc.líquido.de-possd) & 'meu vômito' \\
\hline
\end{tabular}
Fonte: Freitas (2017, pp. 219-220).

Expostos os dados da língua, em se tratando da ocorrência de compostos com marcação morfológica de nomes alienáveis e inalienáveis, cabe fazer algumas considerações sobre esse fenômeno, que permite ver a interação complexa de fatores de ordem morfossintática, semântica, pragmática e discursiva na língua Apurinã, o que será feito na próxima seção.

\section{DISCUSSÃO}

Com os novos dados apresentados, atesta-se que os casos em que compostos ocorrem com marcas de (in)alienabilidade não são tão excepcionais quanto

\footnotetext{
${ }^{18} \mathrm{~A}$ forma ny-suty-ãwĩthe-te também foi dada como correspondendo ao mesmo referente.

${ }_{19}$ Também pode ser com -ne.

${ }^{20}$ Pode ser com - te.

${ }^{21}$ Pode ser com -ne.

${ }^{22}$ Pode ser com -ne.

${ }^{23}$ Também pode ser n-anãnapẽe-ne.
} 
Facundes (2000) considerava, com base nos dados de que dispunha àquela época. $\mathrm{O}$ autor, para explicar os casos que até então eram considerados exceções, em se tratando da ocorrência de compostos com marcas de (in)alienabilidade, afirma:

\begin{abstract}
Se o comportamento distinto desses casos marginais diz algo sobre o status sincrônico de suas estruturas internas ou não, isso precisa ainda ser verificado. Uma possibilidade é a de que esses nomes são formas nominais lexicalizadas que perderam as fronteiras morfológicas internas. Outra é a de que eles são compostos que simplesmente subcategorizam para receber tais marcas morfológicas (FACUNDES, 2000, p.212, tradução nossa).
\end{abstract}

Amparando-se nos dados mais atuais da língua, parece razoável concluir que compostos, especialmente os compostos produtivos, em se tratando da possibilidade de receberem marcas de (in)alienabilidade, não se distinguem dos nomes simples, uma vez que há robustos exemplos de sua ocorrência com tais marcas, tanto em dados lexicais quanto em dados textuais. Dito isso, em casos como xiripi-txi, embora a forma - pi possa estar historicamente relacionada ao nome classificatório para elementos alongados, como em kaikiri-pi (jacaré-alongado) 'cobra jararaca', o que nos permitiria classificar xiripi como um nome composto, de fato, não há evidência de que xiri seja sincronicamente um morfema lexical em Apurinã. Há, então, alguns casos de palavras que se originaram de compostos e que sofreram um certo "desbotamento" de suas fronteiras morfológicas internas. Entre eles estão nomes que têm em sua composição morfemas classificatórios tais como - pi e -na que já se lexicalizaram (ou estão avançando nessa direção) como parte de outros morfemas.

Em todo caso, os dados parecem mostrar que a ocorrência de compostos com a marcação morfológica de nomes alienáveis e inalienáveis está mais ligada a questões de ordem semântica e pragmática do que a questões gramaticais. Em outras palavras, com base, principalmente, nos dados textuais (27 textos) disponíveis em Freitas (2017), verificou-se que, em contextos pragmáticos específicos de uso da língua, ainda que sejam hipotéticos (por exemplo, a posse de certos animais selvagens), é possível a ocorrência de compostos produtivos e, ainda que com frequência menor, de compostos não produtivos e de alguns outros compostos derivados de verbos, em construções de posse alienável ou inalienável. Nesse caso, o tipo de marca, alienável ou inalienável, que os compostos deverão receber é algo lexicalmente condicionado, do mesmo modo como ocorre para os nomes simples.

Os dados textuais utilizados na presente pesquisa foram determinantes para que se chegasse à conclusão de que o uso das marcas de (in)alienabilidade em compostos depende muito mais de questões contextuais (semânticas, pragmáticas, discursivas, variacionais) do que de questões gramaticais. Tais dados textuais foram coletados da seguinte maneira: os falantes foram induzidos a produzir textos pertinentes ao cotidiano deles, pensando em várias situações hipotéticas, mas plausíveis (situações de caça, compra de objetos introduzidos mais recentemente no cotidiano Apurinã, descrição de sensações, de doenças, entre outras) e, com 
isso, foi possível que certas formas que Facundes (2000) não havia conseguido coletar fossem produzidas e posteriormente validadas por falantes de diferentes variedades da língua.

Abaixo, seguem mais alguns exemplos da ocorrência de compostos com marcas de (in)alienabilidade em textos:

(9) Apuuma-ry, ny-tsyy-kywy, ny-tsyy-ĩthu txa-nu.

febre-N.POSSD 1sG-dor.de-cabeça.de 1SG-dor.de-corpo.de AUX-1SG.O

'Sinto febre, dor de cabeça e dor no corpo.'

\section{(10) xiri-pi-txi-nany}

awa-ry ywasaky.

flecha.de.NC.fino, flexível.de-N.POSSD-RESTR haver-3sG.M.o naquele.tempo

'Naquela época só havia flecha.'

(11) Ki-pakyny-pa

quanto-mais-INTENS

pi-xamy-na-ky-te

iki?

'Qual foi o preço da sua espingarda?'

Os exemplos acima, assim como os demais exemplos ilustrativos da ocorrência de compostos com marcas de (in)alienabilidade, ressignificam o status dos nomes compostos na língua Apurinã, antes vistos como uma subclasse à parte, pois considerava-se não incidir sobre eles um dos traços caracterizadores da classe dos nomes na língua, a categoria de posse. Em (9), as formas tsyykywy 'dor de cabeça' e tsyyĩthu 'dor no corpo' são nomes compostos inalienáveis usados na forma possuída. A forma xiripitxi 'flexa' em (10) é um exemplo em texto de um nome inalienável que provavelmente é resquício de um outro que, no passado, foi um inalienável produtivo (como já indicado acima). Já xamynaky 'espingarda', em (11), inclui tanto um nome classificatório, -na, já em processo de lexicalização na língua (dado que é raro a forma xamy- ser usada sem -na) e -ky é um nome classificatório ainda produtivamente usado na língua, resultando em um nome composto alienável. Conclui-se, portanto, com os novos dados, que a marcação de (in)alienabilidade nos nomes em Apurinã ocorre de forma relativamente coesa e sistemática, abrangendo também uma parcela dos nomes compostos, especialmente os produtivos e que, como é natural em todas as línguas do mundo, não está livre das "injunções” do contexto.

Tendo demonstrado que o sistema de marcação alcança pelo menos os compostos produtivos em Apurinã, não se deve ignorar as especificidades contextuais que permitiram observar o uso de compostos em construções de posse. Tais especificidades informam mais sobre os métodos de coleta de dados, mais sobre a natureza do sistema de marcação de posse em Apurinã, ou elas informam algo sobre ambos? No âmbito da variação linguística em Apurinã, há a interferência de fatores diatópicos, diageracionais e diafásicos, entre outros. Há na língua nomes compostos como miriti-ãwĩthe (caititu-chefe.de) 'porco doméstico' ou kema-ãwĩthe (anta-chefe-de) 'vaca', os quais designam nomes de animais introduzidos na cultura Apurinã pelos não indígenas. Quando nomes como estes ocorrem possuídos, a estratégia preferencial usada pelos falantes é 
a posse indireta: ny-pyra miriti-ãwĩthe (1SG-criação.de caititu-chefe.de) 'meu porco doméstico', o mesmo ocorre no caso de kema-ãwĩthe (anta-chefe.de) 'vaca'. No entanto, alguns falantes, além da posse indireta, também aceitam o uso desses compostos com sufixos de posse alienável: ny-miriti-ãwĩthe-ne. Em se tratando do nome para "vaca", alguns falantes usam a forma ny-kema-ãwĩte$n e$, outros ny-kema-ãwĩte-te e há, ainda, falantes que aceitam ambas as formas. Assim, dados os exemplos em questão, a variação dialetal na marcação da posse desses nomes compostos reforça a ideia de que o sistema de marcação de posse em Apurinã é menos rígido em sua aplicação a nomes compostos, visto que não se observa o mesmo tipo de variação dialetal na marcação de posse nos nomes simples.

Portanto, se o sistema de posse se estende aos nomes compostos produtivos de forma coesa, ele o faz dentro de contextos de usos menos amplos que os contextos de uso de nomes simples; contextos mais específicos restringem as manifestações desses compostos em construções de posse e exigem maior sofisticação e criatividade na observação e coleta de dados. Finalmente, é possível que essa aplicação menos rígida do sistema de posse aos nomes compostos favoreça também a variação no uso desses compostos possuídos por falantes de diferentes variedades da língua.

\section{CONSIDERAÇÕES FINAIS}

No presente artigo, revisou-se o status dos nomes compostos na língua Apurinã, inicialmente, apresentando os traços morfossintáticos caracterizadores da classe dos nomes na língua, em que foram fornecidas informações importantes para a compreensão do fenômeno investigado. Em seguida, com base em dados lexicais e textuais disponíveis em Freitas (2017), foi feito um contraponto à análise proposta por Facundes (2000) que, com os dados de que dispunha àquela época, considerava que nomes compostos em Apurinã não podiam receber marcação de posse alienável ou inalienável.

Os dados mais atuais da língua mostraram que há dezenas de casos em que nomes compostos recebem marcas tanto de nomes inalienáveis como de alienáveis e que o uso dessas marcas em compostos depende de uma interação complexa de fatores semânticos, pragmáticos, discursivos e variacionais. Em outras palavras, se por um lado tal uso está sujeito às imposições do contexto em que o falante efetivamente interage por meio da língua, por outro, como uma via de mão dupla, tal contexto é influenciado pelas escolhas desse falante e por seu dialeto, entre outras questões.

Portanto, conclui-se que, ao contrário do que Facundes (2000) sugere, os padrões de marcação de (in)alienabilidade não se restringem a nomes simples e, excepcionalmente, a um ou outro caso de nome composto produtivo. De fato, quando contextos específicos e pragmaticamente plausíveis são oferecidos aos falantes da língua, eles produzem vários outros exemplos de nomes compostos produtivos marcados como alienáveis ou inalienáveis. Assim, pode-se dizer que 
os padrões de marcação de posse em Apurinã se estendem aos nomes compostos produtivos. Por outro lado, o fato de vários dos nomes compostos produtivos terem sido obtidos somente em contextos pragmático-discursivos bastante restritos e de vários outros serem neologismos nos permite concluir também que esses nomes compostos não são pragmaticamente prototípicos entre os (in)alienáveis na língua Apurinã e, talvez por essa razão, o sistema de marcação de posse da língua seja menos rigidamente aplicado a esses nomes.

\section{REFERÊNCIAS}

BARON, Irene; HERSLUND, Michael. Dimensions of Possession. In: BARON, Irene; HERSLUND, Michael; SØRENSEN, Finn. Dimensions of Possession. Amsterdan/ Filadélfia: John Benjamins Publishing Company, 2001, pp. 1-26.

BRANDÃO, A, P, B. Dicionário de Fauna e Flora Apurinã. Belém, Pará: Universidade Federal do Pará, 2006 (Trabalho de Conclusão de Curso).

FACUNDES, Sidney da Silva. Possession and Unpossession in Apurinã (Maipuran). In: LSA Parassession: Languages South of Rio Bravo. Nova Orleans. Conference Proceedings of LSA Parassession: Languages South of Rio Bravo, 1995.

FACUNDES, Sidney da Silva. Noun Categorization in Apurinã (Maipuran). Eugene, Oregon: Depart of linguistics of the University of Oregon, 1994.

FACUNDES, Sidney da Silva. The Language of The Apurinã People of Brazil (Maipure/Arawak). Nova York: Faculty of the Graduate School of State University of New York at Buffalo (Tese de Doutorado), 2000.

FACUNDES, Sidney da Silva, FREITAS, Marília F. P. de. Posse Nominal em Apurinã (Aruák). In: Anais do IV Congresso Internacional de Estudos Linguísticos e Literários na Amazônia [recurso eletrônico], Belém: Programa de Pós-graduação em Letras da UFPA, 2013, pp. 705-715.

FREITAS, M. F. P. de. A Posse em Apurinã: descrição de construções atributivas e predicativas em comparação com outras línguas Aruák. Belém: Programa de Pós-Graduação em Letras, Universidade Federal do Pará (Tese de Doutorado), 2017.

HASPELMATH, Martin. Alienable vs. inalienable possessive constructions. In: Syntactic Universals and Usage Frequency. Leipzig School on Linguistic Diversity, March, 2008, pp. 1-14. Disponível em: http://www.eva.mpg.de/lingua/conference/08_springschool/pdf/course_ materials/Haspelmath_Possessives.pdf. Acesso em: 30 ago. 2020.

HEINE, Bernd. Ways of explaining possession. In: BARON, Irene; HERSLUND, Michael; SØRENSEN, Finn (eds.). Dimensions of Possession. Amsterdã, Filadélfia: John Benjamins Publishing Company, 2001, pp. 311-328 (Typological Studies in Language, vol. 47).

NICHOLS, Johanna. On alienable and inalienable possession. In: Shipley, William. (ed.) In honor of Mary Haas. Berlin: Mouton de Gruyter, 1988, pp.475-521. 
PAYNE, David L. Classification of Maipuran (Arawakan) Languages Based on Shared Lexical Retentious. In: DERBYSHIRE, D. C.; PULLUM, G. K. Handbook of Amazonian Languages languages. [S.1.:s.n.]. 1991, p. 355-499. v. 3.

STASSEN, Leon. Predicative Possession. New York: Oxford University Press, 2009.

Recebido: 21/9/2020

Aceito: $28 / 12 / 2020$

Publicado: 5/1/2020 